\title{
The impact of transformational leadership on innovative capability: Mediating role of employee
} optimism

\author{
Siti Nur Azizah ${ }^{\mathrm{a}, \mathrm{b}^{*}}$, Siti Nurhayati ${ }^{\mathrm{c}}$, Ade Irma Anggraeni ${ }^{\mathrm{b}}$ and Irfan Helmy ${ }^{\mathrm{a}}$
}

${ }^{a}$ STIE Putra Bangsa, Indonesia

${ }^{b}$ Universitas Jenderal Soedirman, Indonesia

${ }^{c}$ Universitas Pekalongan, Indonesia

\section{H R O N I C L E}

\section{Article history:}

Received: June 20, 2020

Received in revised format: August 302020

Accepted: September 18, 2020

Available online:

September 18, 2020

Keywords:

Transformational leadership

Optimism

Innovative capability

Idealized influence

Individualized consideration

\section{A B S T R A C T}

This study aims to examine the mediating effect of employee optimism on the relationship between transformational leadership and innovative capability in the context of batik small and medium enterprises (SMEs) in Indonesia. This study applied the convenience sampling method to survey 186 employees at batik SMEs in Central Java Indonesia through a self-administrated questionnaire. Data were analyzed using smart PLS v.3 to test the hypotheses. The result show that optimism partially mediated the idealized influence of transformational leader behavior on innovative capability. In addition, optimism fully mediated the individualized consideration of transformational leader behavior on innovative capability. This present study provides both empirical and theoretical contribution focusing on leader behavior, employee optimism and innovative capability.

(C) 2021 by the authors; licensee Growing Science, Canada

\section{Introduction}

Le and Lei (2019) argued that swift technological progress and competition in the business environment is required the firms to utilize their potential resources such as human capital to improve innovative capability (IC). IC is the best way for firms to invent value, to develop, and to sustain competitive advantage in the long term (Phong \& Lei, 2019). IC enables the firm to adjust to the lack of certainty of both external and internal environments effectively, and lead the firm's success in the long term (Hong, Zhu, \& Zhou, 2019). But, it is not easy for firms to develop it properly due to a lack of understanding of antecedents of innovation (Lei et al., 2019). To bridge the theoretical gaps, this paper focuses on investigating the impacts of transformational leaders (TL) on the IC of firms based on the mediating role of employees' psychological source namely optimism. Leaders play a decisive role in the failure or success of an organization and each leadership style has a certain significance and influence on organizations' specific outcomes such as innovation (De Vries, Bakker-Pieper, \& Oostenveld, 2010). TL has widely consented as one of the most dominant leadership styles facilitated innovation capabilities for firms (Le \& Lei, 2019). Dimensions of TL; idealized influence and individualized consideration are the two most important aspects that foster innovation capability (Sarros, et al., 2008). Self-efficacy, optimism, hope, and resilience as part of an employee's positive psychological resources (PR) is considered as one of the most significant human resources of every organization (Luthans, Youssef, Avolio, et al., 2007). PR is viewed as strong and intrinsic resources to increase IC within an organization (Sweetman, Luthans, Avey, \& Luthans, 2011). The correlation between specific elements of PR such as optimism and IC is still scarce and limited (Schuckert, Kim, Paek, \& Lee, 2018). Consequently, to provide deeper knowledge of how employee optimism affects IC, this study efforts the empirical evidence. He, An, and Lin (2016) suggested the positive effects of TL on PR which

* Corresponding author.

E-mail address: sitinuraziz@yahoo.com (S. N. Azizah) 
in turn significantly related to the capability of innovation (Sweetman et al., 2011; Wojtczuk-Turek \& Turek, 2015). Research has paid little attention to examining the mediating role of PR or its specific dimensions such as optimism in the connection between TL and IC. This paper used the data gathered from the survey questionnaires in the contexts of batik SME in Kebumen Central Java, Indonesia. We suppose to offer useful direction for SME in developing countries to succeed in improving their IC

\section{Theoretical Framework and Hypotheses}

\subsection{TL and IC}

IC is the process of the identification and execution of new ideas, products, services, procedures, technology, organizational structures, plans, and programs, to intensify organizational performance, and attaining organizational success (Than et al., 2019). Leaders directly affect innovation by creating appropriate conditions within an organization to positively assist the process of generating and implementing activities of innovation (Ha et al., 2019). Previous studies indicated that TLcreates motivation for employees to over their self-interests which allows them unendingly innovate to follow the organizational vision (Bass, Avolio, Jung, \& Berson, 2003). Bass (1985) describes the transformational leaders with four attributes: (1) idealized influence refers transformational leaders' ability in providing a vision and insight of mission, inculcating the pride, and obtaining esteem and trust from employees; (2) intellectual stimulation expresses transformational leaders' capability to encourage rationality and thorough problem solving, and to stimulate the intelligence of followers; (3) inspirational motivation manifests transformational leaders' concerns in sharing or exchanging information with high expectations, utilizing symbols to focus efforts, and conveying key intentions or objectives in simple methods; and (4) individualized consideration reflects transformational leader' interest in meeting employees' needs, coaching, advising, treating each employee individually. This study will examine TL based on two dimensions; idealized influence and individualized consideration because they are two most important aspects that significantly foster an organizational climate for innovation (Sarros et al., 2008). TL is considered as one of the determinant factors that positively and significantly associated with the innovation capabilities of firms, more evidence on the effects of specific dimensions on IC is necessary. We proposed that

Hypothesis 1a: Idealized influence has a positive influence on innovative capability.

Hypothesis 1b: Individualized consideration has a positive influence on innovative capability.

\subsection{TL and Optimism}

According to McColl-Kennedy and Anderson (2002), TL generates a high degree of optimism from the employee through their significant support and consideration, this empirical findings indicated that TL directly affects employee optimism to increase performance. The positive effects of TL on employee optimism, by caring for individuals, and inspiring, leaders can bring employees high confidence in their abilities as well as optimism in the positive results and good prospects of the organization We proposed that:

Hypothesis 2a: Idealized influence has a positive influence on optimism.

Hypothesis 2b: Individualized consideration has a positive influence on optimism.

\subsection{Optimism and IC}

Optimists tend to be more positive facing hard circumstances, they have positive feelings and emotions and persevere to overcome difficulties. They always explore new and effective solutions to successfully resolve the hobbles and maximize the opportunities (Youssef \& Luthans, 2007). The literature review found that optimism plays a dominant role in organizational innovation (Sartori, Favretto, and Ceschi 2013). The optimist employee is motivated to trigger innovative behaviors in the workplace (Abbas and Raja 2015). We proposed that:

Hypothesis 3: Optimism has a positive influence on innovative capability.

\subsection{The mediating role of optimism}

The mediating role of employee optimism in the TL's effect on IC is identified as an important mediator between leadership and the organization's outcomes. Gupta et al. (2017) showed that employee optimism significantly mediates the correlation between leader behaviors in the research and development environment also creative performance behaviors. The mediating role of optimism between leadership and organization's outcomes is clear and shown by current literature, but it is still lacking of how optimism mediates the effects of TL's main traits on IC. We proposed that:

Hypothesis 4a: Optimism mediates between idealized influence and IC.

Hypothesis 4b: Optimism mediates between individualized consideration and IC. 


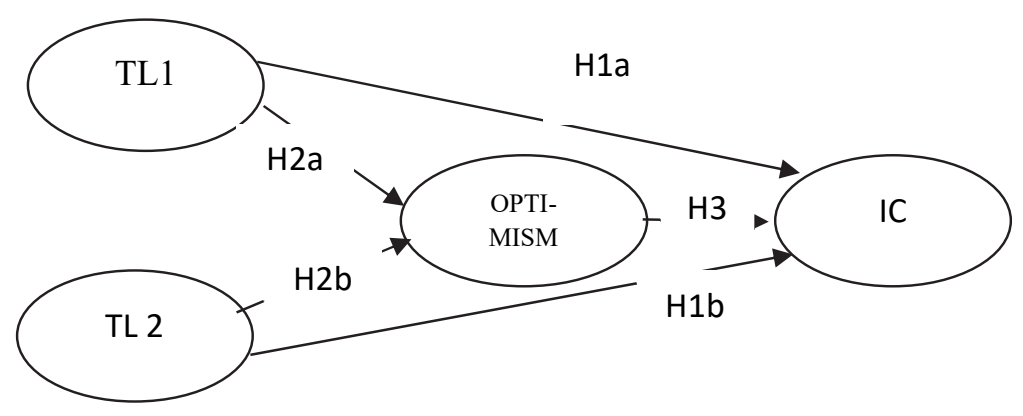

Fig. 1. Research Model

TL 1: Idealized influence TL 2: Individualized consideration

IC: Innovative capability

\section{Research Methodology}

The survey method for collecting data and convenient sampling method used to collect data from creative 20 small and medium firms in Kebumen district Central Java, Indonesia during the period from November to December 2019. 250 questionnaires were distributed and received back 200 in the formal data collection, of which 186 are valid. Respondents were 186 employees on batik SME in Kebumen, Central Java, Indonesia. All the items on the scale are measured on a seven-point Likert scale $(1=$ strongly disagree, $7=$ strongly agree). Respondents were asked about their perceptions of leadership, optimism, and innovative capability. To measure the perception of employees about their leader's transformational behaviors, we use nine items originated from the research of Podsakoff et al. (1990), consist of 5 items of idealized influence and 4 items of individualized consideration. A sample of idealized influence is, "My leader paints an interesting picture of the future for our group". A sample of individualized consideration is "My leader behaves in a manner thoughtful of my personal needs". Optimism consists of 6 items from Luthans et al. (2007). A sample of optimism is "I always look on the bright side of things regarding my job". We use 6 items from Lin (2007) to reflect IC, a sample of IC is "our firm is frequently the first to market new products and services".

\section{Results and Discussion}

The data were analyzed by the structural equation modeling approach of the Partial Least Square technique using Smart PLS 3.0. Before the data were analyzed, it was important to assess its properties. Convergent tests and discriminant validity show that the model is good. The reliability of factors in the model was measured by examining Cronbach's $\alpha$. The cut-off point for reliability is normally taken as 0.7 .

\subsection{Result}

\section{Demographic Characteristic}

According to a data survey in Fig. 1, the majority of respondents were female (74\%). Most of the employee's education is secondary and high school $(72 \%)$ and most of the employees had above 15 years of tenure $(41 \%)$

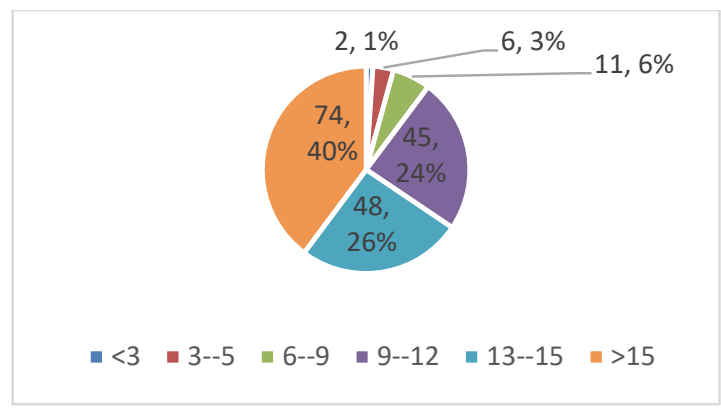

Age

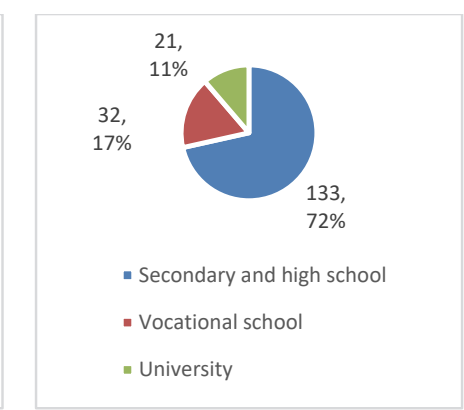

Education

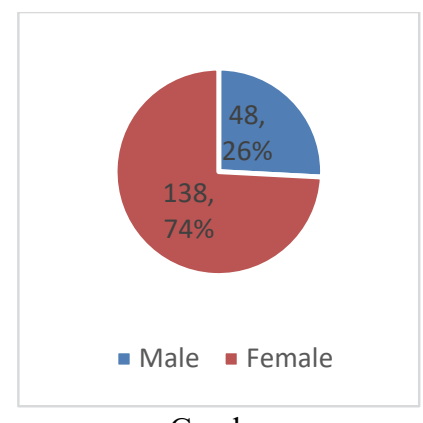

Gender

Fig. 1. Characteristics of Respondents

\section{Measurement model evaluation}

As illustrated in Table 1, minimum requirements are fit with the measurement model. The loading factor of all items above 0.7. AVE (extracted mean value) exceed 0.5 . The composite reliability factor all above 0.7 . Composite reliability ranged from 
0.862 to 0.890 which exceeded the cut of value 0.7 . The Cronbach's alpha coefficient for idealized influence, individual consideration, optimism, and innovative capability were $0.847,0.780,0.817$ and 0.850 indicating an acceptable level of reliability (Hair et al., 2017).

Table 1

Validity and reliability

\begin{tabular}{|c|c|c|c|c|}
\hline Construct and items & Loading Factor & Composite Reliability & AVE & Alpha Cronbach \\
\hline TL1 (Idealized influence) & & 0.890 & 0.620 & 0.847 \\
\hline TL1.1 & 0.746 & & & \\
\hline TL1.2 & 0.790 & & & \\
\hline TL1.3 & 0.760 & & & \\
\hline TL1.4 & 0.874 & & & \\
\hline TL1.5 & 0.768 & & & \\
\hline TL2 (Individualized consideration) & & 0.862 & 0.612 & 0.790 \\
\hline TL2.1 & 0.774 & & & \\
\hline TL2.2 & 0.861 & & & \\
\hline TL2.3 & 0.783 & & & \\
\hline TL2.4 & 0.713 & & & \\
\hline Optimism (Op) & & 0.889 & 0.527 & 0.817 \\
\hline Op1 & 0.724 & & & \\
\hline $\mathrm{Op} 2$ & 0.756 & & & \\
\hline Op3 & 0.883 & & & \\
\hline Op4 & 0.850 & & & \\
\hline Op5 & 0.850 & & & \\
\hline Op6 & 0.815 & & & \\
\hline Innovative Capability (IC) & & 0.867 & 0.576 & 0.850 \\
\hline IC1 & 0.797 & & & \\
\hline IC2 & 0.829 & & & \\
\hline IC3 & 0.844 & & & \\
\hline IC4 & 0.723 & & & \\
\hline IC5 & 0.846 & & & \\
\hline IC6 & 0.831 & & & \\
\hline
\end{tabular}

Discriminant validity is established between two construct association among indicators and greater than that between a construct and any other construct (Hair et al. 2012) as shown in Table 2 as follows

Table 2

Discriminant Validity

\begin{tabular}{ccccc}
\hline & TL1 & TL2 & IC & Optimism \\
\hline TL1 & $\mathbf{0 . 7 8 7}$ & & & \\
TL2 & 0.675 & $\mathbf{0 . 7 8 2}$ & $\mathbf{0 . 7 5 9}$ & \\
IC & 0.700 & 0.759 & 0.751 & $\mathbf{0 . 7 2 6}$ \\
\hline Optimism & 0.602 & 0.708 & & \\
\hline
\end{tabular}

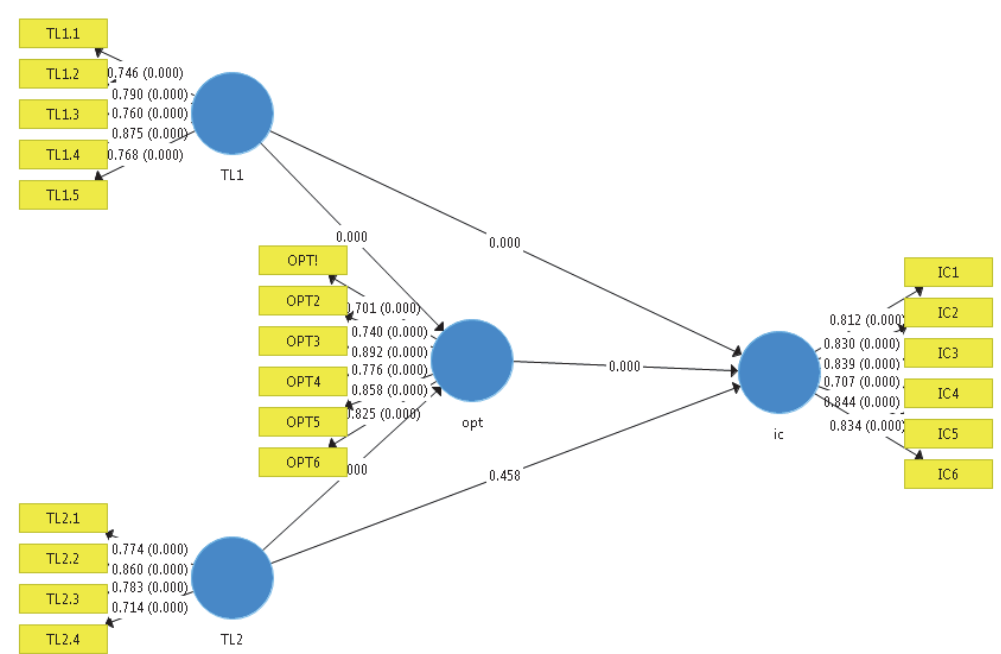

Fig. 2. Measurement Model (Outer Model) 
Table 3

Structural Model Assessment

\begin{tabular}{|c|c|c|c|c|c|}
\hline Variables & Original Samples & STDEV & t-statistic & p-values & Hypothesis \\
\hline $\mathrm{TL} 1 \rightarrow \mathrm{IC}$ & 0.345 & 0.0821 & 4,263 & 0.000 & H1.a supported \\
\hline $\mathrm{TL} 2 \rightarrow \mathrm{IC}$ & 0.079 & 0.099 & 0.079 & 0.458 & H1b not supported \\
\hline TL1 $\rightarrow$ OP & 0.435 & 0.095 & 6.357 & 0.000 & H2a supported \\
\hline $\mathrm{TL} 2 \rightarrow \mathrm{OP}$ & 0.521 & 0.075 & 6,995 & 0.000 & H2b supported \\
\hline $\mathrm{OP} \rightarrow \mathrm{IC}$ & 0.515 & 0.097 & 5.302 & 0.000 & H3 supported \\
\hline \multicolumn{6}{|l|}{ Specified indirect effect } \\
\hline $\mathrm{TL} 1 \rightarrow \mathrm{OP} \rightarrow \mathrm{IC}$ & 0.224 & 0.0623 & 3.501 & 0,000 & H4a supported \\
\hline $\mathrm{TL} 2 \quad \rightarrow \mathrm{OP} \quad \rightarrow \mathrm{IC}$ & 0.269 & 0.0572 & 4.701 & 0.000 & H4b supported \\
\hline
\end{tabular}

Based on Fig. 2 and Table 3 it appears that the p-value on the influence of idealized influence on innovative capability is 0.000 and $t$ statistic is 4.263 . It can be concluded that idealized influence has a positive and significant effect on innovative capability ( $\mathrm{H} 1 \mathrm{a}$ is accepted). Hypothesis $\mathrm{H} 1 \mathrm{~b}$. suggested that individualized consideration has a positive influence on innovative capability. The results also indicate that the $\mathrm{p}$-value is 0.458 and $\mathrm{t}$ statistic is 0.078 . It can be concluded that individualized consideration has an insignificant effect on innovative capability (H1b is rejected). Hypothesis H2a suggested that idealized influence has a positive influence on optimism. Based on Fig. 2 and table 4 it appears that the p-value is 0.000 and $t$ statistic is 6.357. It can be concluded that idealized influence has a significant effect on employee optimism (H2a is accepted). It also appears that the p-value on the influence of idealized influence on employee optimism is 0.000 and $t$ statistic is 6.995. It can be concluded that idealized influence has a positive and significant effect ob employee optimism (H2b is accepted). Hypothesis 3 suggested that employee optimism has a positive influence on innovative capability. Based on figure 2 and table 4 it appears that the p-value is 0.000 and $t$ statistic is 5.302 . It can be concluded that employee optimism has a positive and significant effect on innovative capability (H3 is accepted). Based on Table 4 appears the mediating effect of optimism between idealized influence and IC. It appears that the p-value is 0.000 and $t$ statistic is 3,501 . It can be concluded that $\mathrm{H} 4 \mathrm{a}$ is accepted. Hypothesis H4b suggested that optimism mediates the influence of individualized consideration and IC. Based on table 4 it appears that the p-value is 0.000 and $t$ statistic is 4.701 ( $\mathrm{H} 4 \mathrm{~b}$ is accepted).

\subsection{Discussion}

The firms need a suitable pathway for innovation to create a competitive advantage. The results of this study indicate that the idealized influence of transformational leadership has a positive effect on innovation. TL's behavior in developing, articulating, and inspiring others with leaderships' vision of the future leads the employee to be innovative successfully. This finding supports the findings of Sarros (2018) that idealized influence can increase innovation in companies. However, it contradicts previous findings that individualized consideration of transformational leadership that manifest the concern of TL for employees' personal feelings and needs cannot improve innovative capability directly. This research results showed that transformational leadership directly affects employee optimism as previously found McColl-Kennedy and Anderson (2002). This finding suggested that idealized influence and individualized consideration bring greater optimism and confidence among employees. This study showed that employees who are intrinsically motivated make them more innovative at the workplace (Luthan et al., 2007). The role of optimism that fully mediated leader behavior by providing individual consideration required by SMEs employees in the creation process a new product. The support of a leader is an inexpensive but powerful way to increase optimism in SMEs.

\section{Conclusion}

This research has provided both theoretical and practical contributions. Theoretically, this research has used transformational leadership, optimism and examines its effect on innovative capability. This study has found that optimism could mediate the relationship between transformational leadership and innovative capability. Practically this research tried to focuse on practicing transformational leadership style; motivating employees' thoughts and feeling, SMEs leader can foster employee capabilities for innovation.

\section{References}

Abbas, M., \& Raja, U. (2015). Impact of psychological capital on innovative performance and job stress. Canadian Journal of Administrative Sciences/Revue Canadienne des Sciences de l'Administration, 32(2), 128-138.

Bass, B. M. (1985). Leadership and performance beyond expectations. New York, NY: Collier Macmillan.

Bass, B. M., Avolio, B. J., Jung, D. I., \& Berson, Y. (2003). Predicting unit performance by assessing transformational and transactional leadership. Journal of Applied Psychology, 88(2), 207-218.

De Vries, R. E., Bakker-Pieper, A., \& Oostenveld, W. (2010). Leadership=communication? The relations of leaders' communication styles with leadership styles, knowledge sharing, and leadership outcomes. Journal of Business and Psychology, 25(3), 367-380.

Gupta, M., Shaheen, M., \& Reddy, P. K. (2017). Impact of psychological capital on organizational citizenship behavior mediation by work engagement. Journal of Management Development, 36(7), 973-983.

Ha, A. T. L., Phong, L. B., \& Lei, H. (2019). Leadership and organizational learning: The determinants of innovation speed and innovation quality in Vietnamese firms. Journal of Management and Strategy, 10(1), 29-37. 
Hair, J., Hollingsworth, C., Randolph, A., and Chong, A. (2017). An updated and expanded assessment of PLS-SEM in information systems research. Industrial Management \& Data Systems, 117(3), 442-458.

He, Q.-c., An, Q., \& Lin, P.-x. (2016). Transformational leadership, psychological capital, and frontline sales staffs' service quality: Psychological capital as a mediator. International Journal of u-and e-Service, Science and Technology, 9(7), 309-316.

Hou, B., Hong, J., Zhu, K., \& Zhou, Y. (2019). Paternalistic leadership and innovation: The moderating effect of environmental dynamism. European Journal of Innovation Management, 22(3), 562-582.

Le, P. B., \& Lei, H. (2019). Determinants of innovation capability: The roles of transformational leadership, knowledge sharing, and perceived organizational support. Journal of Knowledge Management, 23(3), 527-547.

Lin, H.-F. (2007). Knowledge sharing and firm innovation capability: An empirical study. International Journal of Manpower, 28(3/4), 315-332.

Luthans, F., Youssef, C. M., Avolio, B. J., et al. (2007). Psychological capital: Developing the human competitive edge Oxford, UK: Oxford University Press.

McColl-Kennedy, J. R., \& Anderson, R. D. (2002). Impact of leadership style and emotions on subordinate performance. The Leadership Quarterly, 13(5), 545-559.

Podsakoff, P. M., MacKenzie, S. B., Moorman, R. H., \& Fetter, R. (1990). Transformational leader behaviors and their effects on followers' trust in leader, satisfaction, and organizational citizenship behaviors. The Leadership Quarterly, 1(2), $107-142$

Sarros, J. C., Cooper, B. K., \& Santora, J. C. (2008). Building a climate for innovation through transformational leadership and organizational culture. Journal of Leadership \& Organizational Studies, 15(2), 145-158.

Sartori, R., Favretto, G., \& Ceschi, A. (2013). The relationships between innovation and human and psychological capital in organizations: a review. The Innovation Journal, 18(3), 1-18.

Sweetman, D., Luthans, F., Avey, J. B., \& Luthans, B. C. (2011). Relationship between positive psychological capital and creative performance. Canadian Journal of Administrative Sciences/Revue Canadienne des Sciences de l'Administration, 28(1), 4-13.

Youssef, C. M., \& Luthans, F. (2007). Positive organizational behavior in the workplace: The impact of hope, optimism, and resilience. Journal of Management, 33(5), 774-800.

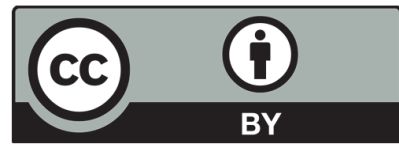

(C) 2020 by the authors; licensee Growing Science, Canada. This is an open access article distributed under the terms and conditions of the Creative Commons Attribution (CC-BY) license (http://creativecommons.org/licenses/by/4.0/). 